\title{
FUZZY SYSTEM OF DISTRIBUTION OF BRAKING FORCES ON THE ENGINES OF A MOBILE ROBOT
}

\author{
Maxim Bobyr ${ }^{1 \mathrm{a}}$, Vitaliy Titov $^{1}$, Alexander Belyaev ${ }^{2}$ \\ ${ }^{1}$ Southwest State University, Department of Computer Engineering, 305040, Kursk, Russia \\ ${ }^{2}$ Tomsk State University, 634050, Tomsk, Russia
}

\begin{abstract}
The article presents a fuzzy system of distribution of braking forces on the engines of a mobile robot during its lifting and going down. The block diagram of the system of distribution of braking forces and location of sensors on a mobile robot is given in the paper. Also, fuzzy mathematical model of redistribution of braking forces depending on the conditions of the movement a mobile robot is shown in the article. The result of the simulation of control parameters are presented in the article. The control system of a mobile robot is demonstrated on the example of an autonomous mini-robot on platform Pirate under the control of microprocessor Arduino Mega 2560.
\end{abstract}

\section{Introduction}

Today, significant attention is paid to the process of robotics in different industrial spheres $[1,2]$. The growth of quantity of robotic systems is increased due to the rapid growth of microprocessor systems. One example of such systems is microprocessor modules Arduino: Uno, Leonardo, Mega et al. As a rule, the control system of a mobile robotincludes a microprocessor control board, sensors which analyze the location and / or the a spatial orientation and the program algorithms of its control.

During the movement of a mobile robot special regimes appear. For example, the movement of a mobile robot along cross-country, in particular its lifting and going down. Thus, during braking the front wheels received greater load than the back ones. There are different systems of force distribution allowing to avoid moments of wheel lockup. If control of a mobile robot uses the concept of Anti-lock braking system (ABS), it successfully controls the unlocking only of the front wheels [3]. Consequently, the turn of a mobile robot is possible during its braking. The researches have shown that the braking forces on the wheels are distributed equally. However, the clutch of the wheels with surfacewhere a mobile robot moves is different. When the concept of Electronic Brake Distribution (EBD) is used force on the wheels is distributed depending upon their speed of rotation [4].Given system consists of three components: a microprocessor control unit, sensors of speed rotation of wheels and actuating mechanisms of control of force distribution on the wheels. It works as follows. A microprocessor unit processes

${ }^{a}$ Corresponding author: maxbobyr@gmail.com 
information from the wheel speed sensors. Based on these data a microprocessor unit concludes which wheels have better clutch with the road surface. After that, EBD redistribute force on the wheels.

When used in mobile robots accelerometers, which are not used in the ABS and EBD system possibilities of distribution braking forceses system are expanded. So accelerometers allow to define the angles of lifting and / or going down during the movement of mobile robots. This allows to make pre-correction in the control program of the movement of a mobile robot, for example, to increase or decrease the speed of rotation of the wheels, and in extreme cases to change the direction of their rotation during going down which has a large angle of declination [5].

At the present time intelligent methods of decision-making control, used in mobile robots are neural networks, evolutionary algorithms, multi-agent systems and adaptive neuro-fuzzy inference system [6-8]. In some cases used the combination of these models. As a rule the selection of one of the aforecited decision-making methods depends on the dynamics of movement of a mobile robot. Thus, it is necessary to take into account the fact that memory of the microcontroller is limited. Therefore, the correct choice of decisionmaking method also will allow to minimize the program code of control of a mobile robot. The authors propose for increasing efficiency of decision-making control to use adaptive neuro-fuzzy inference system.

\section{Structural scheme of a mobile robot}

To solve the problem of the movement of a mobile robot along cross-country the authors suggest usingan experimental model assembled on the Pirate 4WD platform shown in Figure 1.

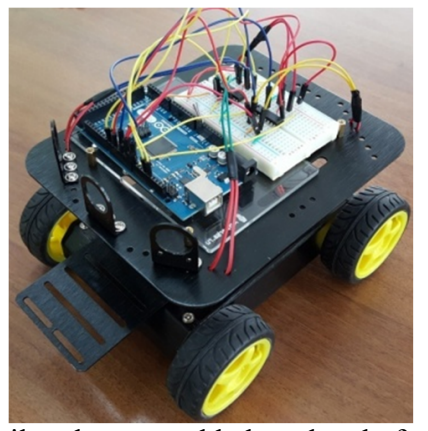

Figure 1. Experimental model of a mobile robot assembled on the platform Pirat 4WD.

The mobile robot consists of a control board - Arduino Mega 2560, two drivers (Hbridge circuit, L293D) for control of four engines of mobile robot, three-axis accelerometer - LIS331DLH. An accelerometer is a part of the IMU-sensor (Inertial Measurement Unit) possessing 10 degrees of freedom. Also IMU-sensor includes a gyroscope, magnetometer (digital compass) and barometer.

In Figure 2 given scheme of the connection H-bridge circuits and an accelerometer to control board of a mobile robot is presented. 


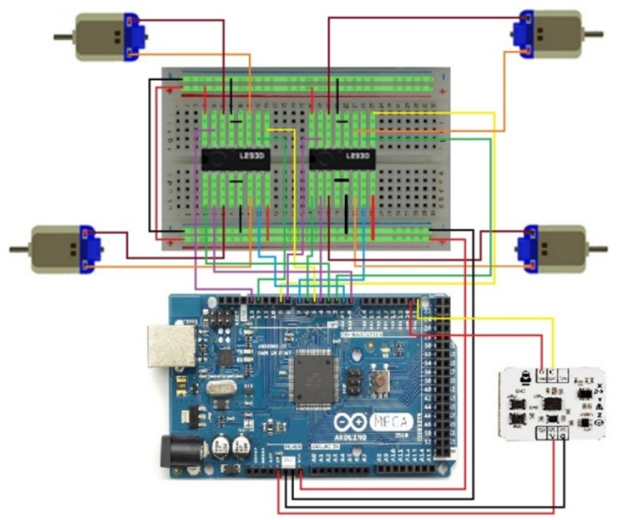

Figure 2. Scheme of the connection H-bridge circuits and an accelerometer to control board.

The concept of interconnection of sensors and a mobile robot with a fuzzy inference system of distribution of braking forces on its wheels is shown in Figure 3.

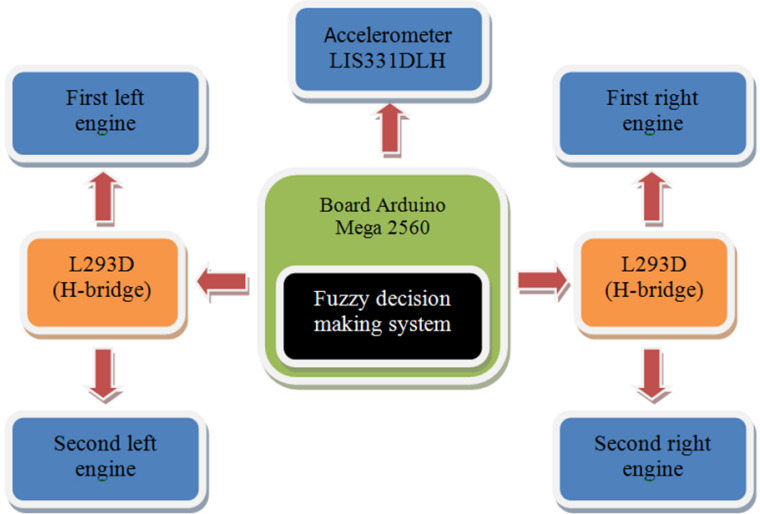

Figure 3. The concept of interconnection of sensors and a mobile robot with fuzzy inference system.

In an experimental model of a mobile robot (Figure 1) are used two DC motors (engines). They work on the basis of pulse-width modulation. Signal strength transmitted to them from the microprocessor unit changes from high $(5 \mathrm{~V}$ or Speed $=255)$ to low $(0 \mathrm{~V}$ or Speed $=0)$ levels. Therefore, the control signal transmitted from the microprocessor unit on L293D is in the range from 0 to 255 . Let the signal be variable Speed. Thus, the larger value of variable Speed is, the greaterrotation speed of the wheels of a mobile robot is.

Measure of tilt angles during the movement of a mobile robot along cross-country is carried by using three-axis accelerometer. In the initial position of the accelerometer $\mathrm{X}$ and $\mathrm{Y}$ axes are in the horizontal plane but z-axis is orthogonal to $x$ and $y$-axis (Figure 4).

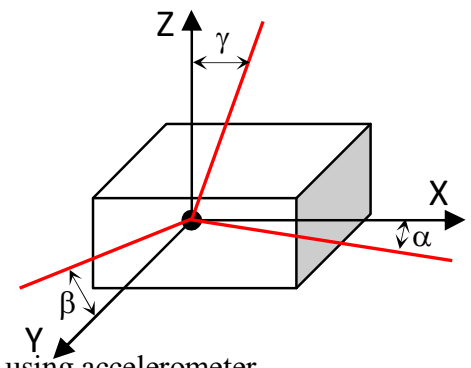

Figure 4. Measuring of tilt angles with using accelerometer. 
The values of the tilt angles (Figure 4) are calculated using the following formulas:

$$
\begin{aligned}
& \alpha=\arctan \left(\frac{X}{\sqrt{Y^{2}+Z^{2}}}\right) \\
& \beta=\arctan \left(\frac{Y}{\sqrt{X^{2}+Z^{2}}}\right) \\
& \gamma=\arctan \left(\frac{Z}{\sqrt{X^{2}+Y^{2}}}\right)
\end{aligned}
$$

\section{Fuzzy model of distribution of braking forces on the engines of a robot}

Formation of braking forces, that is the rotational speed of wheels of a mobile robot, depends on conditions of its movement. Let the speed of rotation of the wheels of a mobile robot (Speed) is output variable. Let the tilt angles defined to formulas (1)-(3) are input variables of the fuzzy system. Further, consider the fuzzy MISO-system having two input variables:

and one input variable:

$$
\begin{aligned}
& X=\left\{x_{1}\right\}+\left\{x_{2}\right\}+\left\{x_{3}\right\} \\
& Y=\left\{y_{1}\right\}+\left\{y_{2}\right\}+\left\{y_{3}\right\}
\end{aligned}
$$

$$
\text { Speed }=\left\{s_{1}\right\}+\left\{s_{2}\right\}+\left\{s_{3}\right\}+\left\{s_{4}\right\}+\left\{s_{5}\right\}
$$

where $x_{1}, \ldots, x_{3} ; y_{1}, \ldots, y_{3}$ areterms of first and second input variables of fuzzy sets $X$ and $Y$; $s_{1}, \ldots, s_{5}$ areterms of output variable of fuzzy set Speed.

Input and output variables are described by parametric triangular membership functions (MF), which are shown in Figure 5, where $\mu$ (x), $\mu$ (y), $\mu$ (s) are the membership functions of fuzzy sets X, Y, Speed, respectively[9, 10].

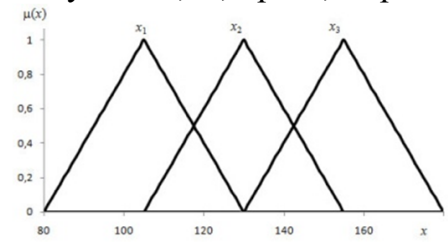

a)

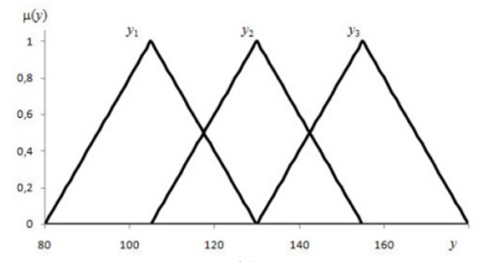

b)

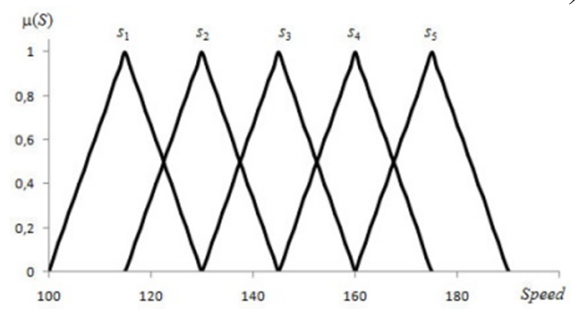

c)

Figure 5. MF: (a) the first input MF; (b) the second input MF; (c) the output MF.

Fuzzy base of knowledge is set by fuzzy rules (FR) and is shown in Table 1. 
Table 1.Fuzzy base of knowledge.

\begin{tabular}{|c|c|c|c|c|c|c|c|c|c|c|c|}
\hline FR & \multicolumn{2}{|c|}{ If } & Then & FR & \multicolumn{2}{|c|}{ If } & Then & FR & \multicolumn{2}{|c|}{ If } & Then \\
\hline $\mathrm{FR}_{1}$ & \multirow{3}{*}{$x_{1}$} & $y_{1}$ & $s_{1}$ & $\mathrm{FR}_{4}$ & \multirow{3}{*}{$x_{2}$} & $y_{1}$ & $S_{2}$ & $\mathrm{FR}_{7}$ & \multirow{3}{*}{$x_{3}$} & $y_{1}$ & $s_{3}$ \\
\hline $\mathrm{FR}_{2}$ & & $y_{2}$ & $s_{2}$ & $\mathrm{FR}_{5}$ & & $y_{2}$ & $s_{3}$ & $\mathrm{FR}_{8}$ & & $y_{2}$ & $S_{4}$ \\
\hline $\mathrm{FR}_{3}$ & & $y_{3}$ & $s_{3}$ & $\mathrm{FR}_{6}$ & & $y_{3}$ & $s_{4}$ & $\mathrm{FR}_{9}$ & & $y_{3}$ & $S_{5}$ \\
\hline
\end{tabular}

Defuzzification is carried on the base of the method of center of gravity or using method of difference areas [11-15].

$$
\text { Speed }_{C o G}=\frac{\int_{\min }^{\max } s \mu^{\prime}(s) d s}{\int_{\min }^{\max } \mu^{\prime}(s) d s}
$$

where min, $\max$ are limits of integration of fuzzy sets; $\mu^{\prime}(s)$ is out put fuzzy set after aggregation.

To realize the method of difference areas it's necessary to do the following steps.

Step 1. Determine the total area of the shape output value.

Step 2. Determine the height of degrees of applicability of output terms.

Step 3. Determine areas of every output terms depending on the height values of the degrees of applicability.

Step 4. Determine the total area of the shape with transformed membership functions.

Step 5. Determine the ratio of the total area of the shape of the output variable and the total area of the shape with transformed membership functions.

Step 6. Determine the proportional relationship.

\section{Experimental research}

For the analysis of fuzzy model of distribution of braking forces is conducted numerical simulation. The simulation was performed with using in the fuzzy inference of hard and soft arithmetic operations of finding the minimum and maximum. During defuzzification were used the models of center of gravity and the difference of areas. After defuzzification surfaces of response of output variable were obtained (Figures 6,7).

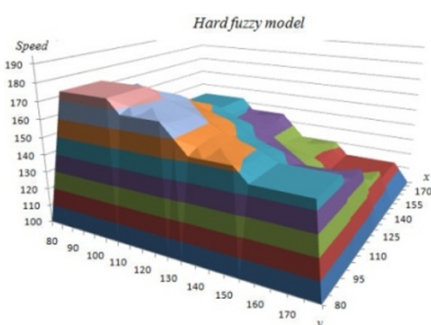

a)

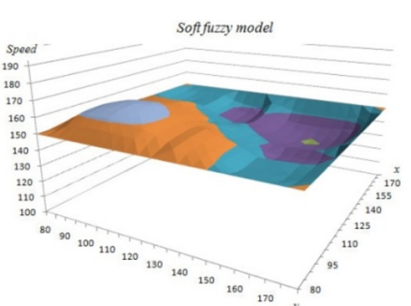

b)

Figure 6. Defuzzificationon the base of CoG model with usage of: (a) hard arithmetic operations; (b) soft arithmetic operations. 


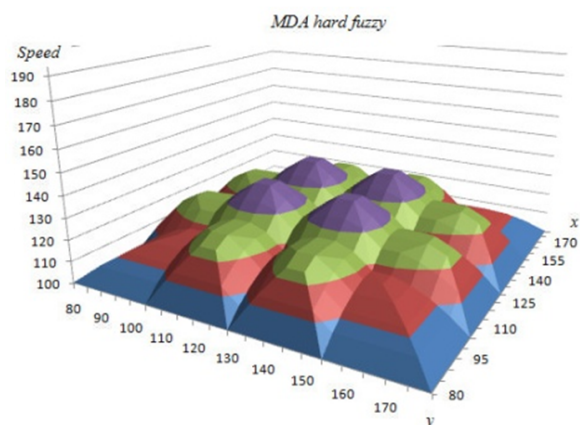

a)

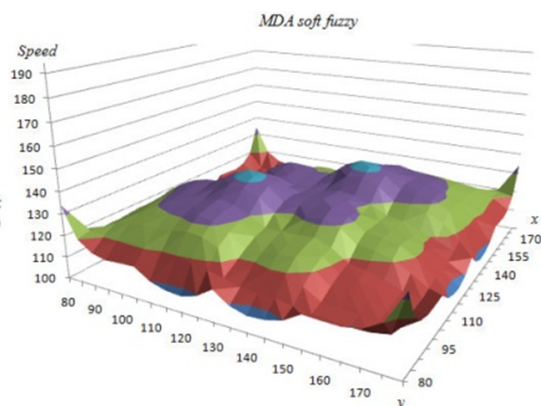

b)

Figure 7. Defuzzification on the base of MDA with usage: a) hard arithmetic operations; b) soft arithmetic operations.

The simulation showed that during using in the fuzzy inference soft of arithmetic operations the surface of response has more smooth appearance and is additive.

\section{Conclusion}

The result of research of fuzzy system distribution of braking forces on the engines of a mobile robot showed that to obtain smoother surface of response of the crisp output variable in fuzzy inference it's necessary to use soft arithmetic operations. The presented simulation showed that accuracy of fuzzy systems increased more than 10 times during usage of soft formulas. Proposed in the paper fuzzy control system of a mobile robot's movement allows to increase the speed of the adoption of the control solution more than $15 \%$.

\section{Acknowledgment}

The research was done with the support of the RF President's grant for young scientists MD-2983.2015.8, and the program of improving competitiveness of the TSU (project No. 8.2.31.2015).

\section{References}

[1] O. Kilincci, S.A. Onal, Expert Systems with Applications 38,9656 (2011) doi:10.1016/j.eswa.2011.01.159

[2] H.-S. Park, S.-B. Cho, Information Systems 36, 1124 (2011) doi:10.1016/j.is.2011.04.005

[3] R.-E. Precupa, M.-C. Sabaua, E.M. Petriu, Applied Soft Computing 27,575(2015) doi:10.1016/j.asoc.2014.07.004

[4] Masao Nakazawa, Osamu Isobe, Sadahiro Takahashi, Yoshito Watanabe, JSAE Review 16,479 (1995)

[5] P. Staufer, H. Gattringer, Mechatronics 22, $1043 \quad$ (2012) doi:10.1016/j.mechatronics.2012.08.009

[6] N. Mendes, P. Neto, Expert Systems with Applications 42, 8929 (2015)doi:10.1016/j.eswa.2015.07.047

[7] N.-B.Hoanga, H.-J. Kang, Neurocomputing 188, $12 \quad$ (2016) doi:10.1016/j.neucom.2015.02.101 
[8] D. Bucura, G. Iaccab, M. Gaudesic, G. Squilleroc, A. Tonda, Applied Soft Computing 40, 416 (2016)doi:10.1016/j.asoc.2015.11.024

[9] M.V. Bobyr, V.S.Titov, A.A. Nasser, Journal of Machinery Manufacture and Reliability 44,633 (2015) doi: 10.3103/S1052618815070067

[10] I.V. Chernova, S.A. Sumin, M.V. Bobyr, S.P. Seregin, Biomedical Engineering 49, 263 (2016)doi:10.1007/s10527-016-9545-y

[11] M.V. Bobyr, S.A .Kulabukhov, Vestnik komp'iuternykh i informatsionnykh tekhnologii 9, 32(2015)doi:10.14489/vkit.2015.09.pp.032-041

[12] M.V. Bobyr, N.A. Milostnaya, Angineering and automation problems 3, 27(2015)

[13] W.V. Leekwijck, E.E. Kerre, Fuzzy Sets and Systems 108, 159(1999) doi:10.1016/S0165-0114(97)00337-0

[14] A. Chandramohan, M.V.C.Rao, M.S. Arumugam, Soft Computing 10, 1047 (2006) doi: 10.1007/s00500-005-0042-6

[15] H.R. Mahdiani, A. Banaiyan, M.H.S. Javadi, S.M. Fakhraie, C. Lucas, Engineering Applications of Artificial Intelligence 26, 162 (2013) doi: 10.1016/j.engappai.2012.07.001 